In addition, Safekids acquired a creatives made for children, by children.

Conclusion Effective engagement with children increased awareness and acceptance of wearing a helmet.

Key concepts supported effective intersectoral collaboration between Safekids, schools, families, communities and the media to reduce the risk of injury to children.

\section{DANGEROUS STUDENT PASSENGER DROP-OFF, PEDESTRIAN BEHAVIOURS AND THE BUILT ENVIRONMENT NEAR SCHOOLS}

\begin{abstract}
1,2 Linda Rothman, ${ }^{1}$ Andrew Howard, ${ }^{3}$ Ron Buliung, 1,2Sarah A Richmond, ${ }^{2}$ Colin Macarthur, ${ }^{2}$ Axlison Macpherson. ${ }^{1}$ York University, Toronto, Canada; ${ }^{2}$ Hospital for Sick Children Toronto, Canada; ${ }^{3}$ University of Toronto Mississauga, Mississauga, Canada
\end{abstract}

\subsection{6/injuryprev-2016-042156.72}

Background Dangerous drop-off of student passengers and pedestrian behaviours near schools have not been well described despite the potential for pedestrian motor vehicle collisions (PMVC). Safe environments are required for children around schools. Passenger drop-off and child pedestrian behaviours are described by occurrence of child PMVC and built environment (BE) features in Toronto, Canada.

Methods Dangerous passenger drop-off and pedestrian behaviours observations were done in 2015. Child PMVCs from 2000-2013, age 4-12 years, were mapped near 100 schools. Case schools had $\geq 1$ collision and control schools had 0 . Dangerous driving/parking, unsafe pedestrian crossings, distracted walking and disobeying crossing controls/guards were compared using chi-square statistics by case/control status or BE features: downtown/inner suburbs, school crossing guards and designated car drop-off areas.

Results Dangerous drop-off and/or pedestrian behaviours occurred at over 92\% of schools. A greater proportion of case schools had children crossing at uncontrolled midblocks $(97 \%$ vs. $78 \%$ controls). A greater proportion of inner suburb schools versus downtown had cars double-parked $(52 \%$ vs. $28 \%)$ and parked blocking crossing controls (25\% vs. $4 \%)$. A smaller proportion of schools with crossing guards versus without had cars parked blocking crossing controls (10\% vs. $25 \%$ without) and drivers texting (5\% vs. 22\%). A smaller proportion of schools with designated drop-off areas versus without, had cars reversing dangerously (76\% vs. 55\%), parked blocking crossing controls (31\% vs. $10 \%)$, children crossing at uncontrolled midblocks (78\% vs. 95\%) and between parked cars (48\% vs. $76 \%)$.

Conclusions Dangerous student drop-off and pedestrian behaviours were pervasive at schools. Occurrence of behaviours was related to the $\mathrm{BE}$; particularly designated car-drop off areas. Adaptations to the BE near schools may defer dangerous behaviours and provide a safer child pedestrian environment.

\section{ASSOCIATION OF MATERNAL DEPRESSION AND ANXIETY WITH CHILDREN'S INJURY RISK: A PROSPECTIVE COHORT}

Ruth Baker, Elizabeth Orton, Denise Kendrick, Laila J Tata. The University of Nottingham, UK

10.1136/injuryprev-2016-042156.73
Background Maternal depression and anxiety are common in the early years following childbirth and are associated with children's health outcomes. The impact of maternal depression on childhood injuries is underexplored, with existing studies relying on maternal reporting of injury occurrences. Using linked population healthcare databases from England, we assessed the association between episodes of maternal depression and/or anxiety and the incidence of three common childhood injuries.

Methods We conducted a prospective cohort study of 209,418 mother-child pairs who had linked primary care and hospitalisation data from the Clinical Practice Research Datalink and Hospital Episode Statistics from 1997-2014. Episodes of maternal depression and/or anxiety were identified using diagnostic codes, prescriptions and hospitalisation records. Adjusted incidence rate ratios (aIRR) for the risk of child poisonings, fractures and burns during episodes of maternal mental health episodes were estimated using Poisson regression.

Results 55,431 children (26.5\%) were exposed to one or more episodes of maternal depression and/or anxiety between birth and their fifth birthday. During follow-up 2,772 poisoning, 6,252 fracture and 4,316 burn events occurred. Child poisoning risk increased during episodes of maternal depression (aIRR 1.61, 95\% confidence interval 1.39-1.87), depression with anxiety $(2.10,1.74-2.53)$ and anxiety alone $(1.61,1.07-2.42)$. A similar pattern was seen for burns, with the greatest risk during episodes of depression with anxiety $(1.53,1.28-1.82)$. Fracture risk only increased during episodes of depression alone (1.16, 1.04-1.30). Conclusions Episodes of maternal depression and/or anxiety were associated with increased risks of child poisonings and burns. Prompt identification and treatment of maternal depression and/or anxiety and provision of safety advice (e.g. safe medication storage) to mothers with depression and/or anxiety may reduce child injury risk.

\section{TEKO - SAFETY IN SCHOOL SPORTS IN FINLAND}

Anne-Mari Jussila, Raija Oksanen, Jari Parkkari. Tampere Research Centre of Sports Medicine, UKK Institute, Finland

\subsection{6/injuryprev-2016-042156.74}

Background In Finnish schools sport injuries happen mostly in physical education (PE) classes and in recess. A remarkable part of the injuries can be prevented. TEKO - Safety in School Sports (2010-) is part of the Sports and Exercise Safety program LiVE. The primary target group for TEKO is PE and health education (HE) teachers in secondary schools. Safety promotion focuses on 10 segments; physical activity (PA), sports skills, maturation, nutrition, rest and sleep, environment and equipment, health care, atmosphere and rules, injuries and support network.

Objective TEKO has produced free of charge educational material and methods to internet to encourage PA, to increase quality and contents of PE and to promote safety of sports widely in school settings. TEKO has built up education material e.g. information packages, electric homeworks, videos and PP-slides for teaching. The main delivery channel is www.tervekoululainen.fi.

Results After 6 years websites ha 10000 visits per month and YouTube videos have been watched 43000 times. TEKO has kept over 60 education events. TEKO has also built up a large collaborator network, which enables the spreading of sports safety message.

A web-based project evaluation survey was done in 2013 to PE and HE teachers $(n=900)$. The response rate was $20 \%$. The 